\title{
Facilitated Anion Transport Induces Hyperpolarization of the Cell Membrane that Triggers Differentiation and Cell Death in Cancer Stem Cells
}

\author{
Vanessa Soto-Cerrato,${ }^{\dagger}$ Pilar Manuel-Manresa,${ }^{\dagger}$ Elsa Hernando, ${ }^{\ddagger}$ Silvia Calabuig-Fariñas,,, Il Alicia Mar- \\ tínez-Romero, ${ }^{\|}$Víctor Fernández-Dueñas, ${ }^{\perp}$ Kristoffer Sahlholm, ${ }^{\perp \bullet}{ }^{\bullet}$ Thomas Knöpfel, ${ }^{\#}$ María García- \\ Valverde, ${ }^{\dagger}$ Ananda M. Rodilla, ${ }^{\dagger}$ Eloisa Jantus-Lewintre, ${ }^{\S, \times}$ Rosa Farràs, ${ }^{\|}$Francisco Ciruela, ${ }^{\perp, \Delta}$ Ricardo \\ Pérez-Tomás, ${ }^{*, \dagger}$ and Roberto Quesada*,* \\ ${ }^{\dagger}$ Cancer Cell Biology Research Group, Department of Pathology and Experimental Therapeutics, Faculty of Medicine, Uni- \\ versity of Barcelona, Barcelona, Spain \\ "Departmento de Química, Universidad de Burgos, 09001 Burgos, Spain \\ ${ }^{\S}$ Fundación de Investigación Hospital General Universitario de Valencia, Valencia, Spain \\ 'Centro de Investigación Príncipe Felipe, Valencia, Spain \\ ${ }^{\perp}$ Unitat de Farmacologia, Departament Patologia i Terapèutica Experimental, Facultat de Medicina, IDIBELL. Universitat de \\ Barcelona, L'Hospitalet de Llobregat, Barcelona, Spain \\ 'Department of Neuroscience, Karolinska Institute, Solna, Stockholm, Sweden \\ \#Division of Brain Sciences, Imperial College London, London SW7 2AZ, United Kingdom \\ IIDepartment of Pathology, Universitat de València, Valencia, Spain. \\ ${ }^{\times}$Department of Biotechnology, Universitat Politècnica de València, Valencia,Spain \\ ${ }^{\Delta}$ Department of Biochemistry and Microbiology, Faculty of Sciences, University of Ghent, Gent, Belgium
}

\begin{abstract}
Facilitated anion transport potentially represents a powerful tool to modulate various cellular functions. However, research into the biological effects of small molecule anionophores are still at an early stage. Here we have used two potent anionophore molecules inspired in the structure of marine metabolites tambjamines to gain insight into the effect induced by these compounds at the cellular level. We show how active anionophores, capable of facilitating the transmembrane transport of chloride and bicarbonate in model phospholipid liposomes, induce acidification of the cytosol and hyperpolarization of plasma cell membranes. We demonstrate how this combined effect can be used against cancer stem cells (CSCs). Hyperpolarization of cell membrane induces cell differentiation and loss of stemness of CSCs leading to effective elimination of this cancer cell subpopulation.
\end{abstract}

\section{INTRODUCTION}

Transmembrane ion channels and pumps are sophisticated cellular machineries involved in many biological processes. As such, ion channels constitute one of the main drug targets in medicinal chemistry. An estimated $13 \%$ of currently approved drugs have ion channels as their main therapeutic target, being used for the treatment of a variety of disease conditions. ${ }^{1}$ The most successful strategy to modulate transmembrane ion flux is to use small molecules activators or blockers of endogenous proteins. Nevertheless, there is an intense interest in designing artificial ion channels and ionophores. ${ }^{2,3}$ In particular, cation selective ionophores are widely used as antibiotics and research tools. In the last few years, the development of small molecules capable of facilitating the transmembrane transport of anions has emerged as an active research field..$^{4-6}$ A number of molecules inspired by naturally occurring anionophores such as prodiginines or by synthetic molecules containing amide, (thio)urea, or (thio)squaramide hydrogen bond donors have been characterized as efficient anion transporters. ${ }^{7-10}$ The potential biological applications of these compounds have been less explored. In a seminal work, Magda, Sessler et. al. linked the anionophoric activity of prodigiosin-like molecules with their anticancer activity. ${ }^{11}$ Further work by different research groups delineated relationships between the transmembrane transport of anions and the cytotoxicity induced by some of these compounds. ${ }^{12}$ Very recently, Gale, Sessler, Shin and coworkers have demonstrated how diamide-strapped calix[4]pyrroles induced apoptosis via a caspase-dependent pathway as a result of the facilitated sodium and chloride influx promoted by these derivatives. ${ }^{13}$

Potentially, facilitated transmembrane transport of chloride and bicarbonate (the most abundant anions in biological environments) could impact on cellular ion homeostasis, $\mathrm{pH}$ levels and membrane potentials. These are key parameters for cell survival and there is a growing body of evidence showing their relationships with cancer development and progression. ${ }^{14}$ Dysregulated $\mathrm{pH}$ has been recognized as a hallmark of cancer. Cancer cells show a reversed $\mathrm{pH}$ gradient compared to normal 


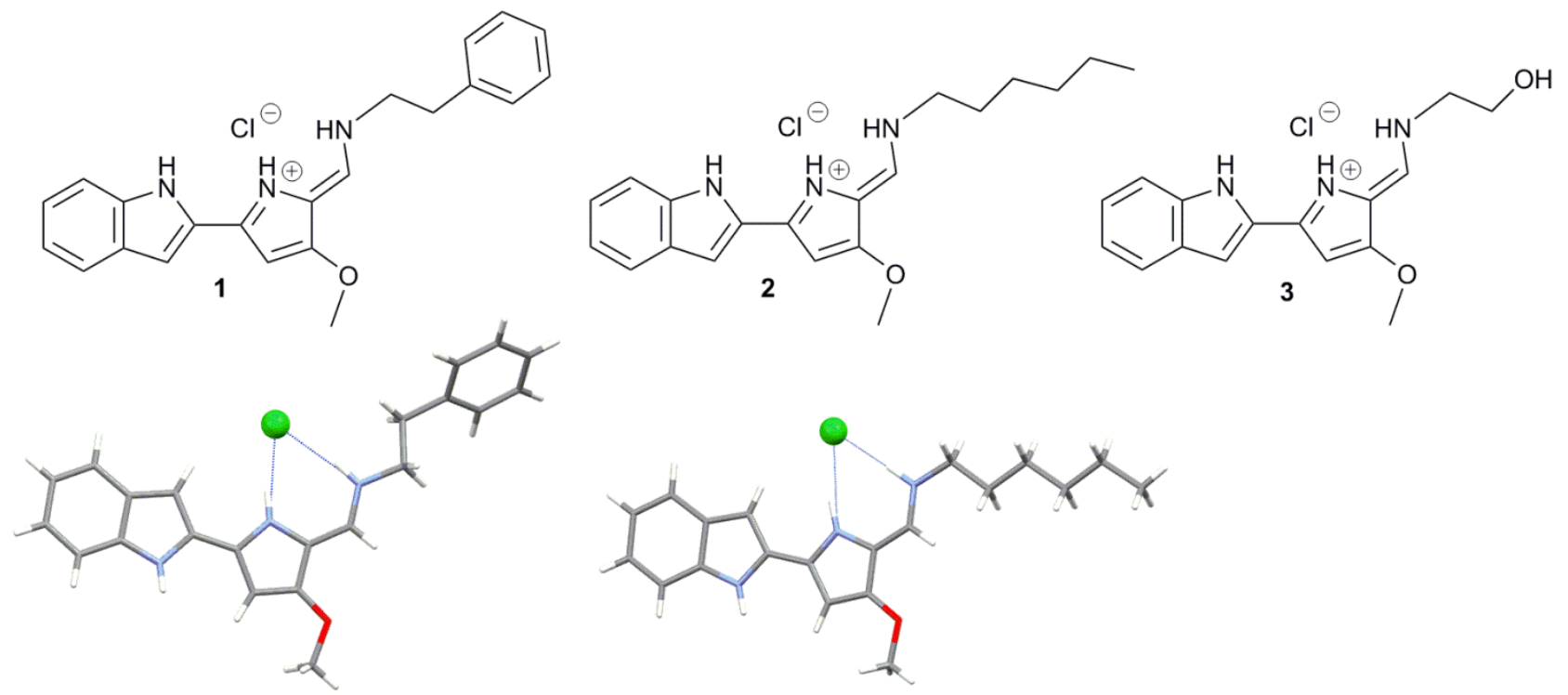

Figure 1. Studied compounds. (a) molecular structures of compounds $\mathbf{1}$ - 3. (b) X-Ray structures of compounds $\mathbf{1}$ and $\mathbf{2}$ as hydrochloride salts.

differentiated cells, with intracellular $\mathrm{pH}(\mathrm{pHi})$ higher than extracellular $\mathrm{pH} .{ }^{15}$ This reversed gradient is regulated by ion channels and pumps, and facilitates cancer progression being permissive for some of the acquired characteristics of cancer cells, such as sustained proliferative signalling or resistance to cell death. ${ }^{16}$ Membrane potential $(\mathrm{Vm})$ also play key roles in cancer development and cell differentiation. ${ }^{17}$ Nonproliferating, terminally differentiated somatic cells, such as muscle cells and neurons, are characterized by their hyperpolarized Vm, whereas proliferative cells, especially rapidly proliferating tumour cells, displayed depolarized Vm. Interestingly, cancer stem cells (CSCs), a tumor cell subpopulation that exhibits tumor-initiating capacity, self-renewal in serial transplantation assays and contributes to acquired chemotherapy resistance in cancer, ${ }^{18}$ need to maintain a depolarized $\mathrm{Vm}$ in order to preserve their stemness capacities. ${ }^{19,20}$ Therefore, $\mathrm{pH}$ modulation to avoid cancer cells acquired advantages, as well as, suppression of stemness properties through the modulation of plasma membrane potential might be promising new therapeutic strategies for cancer treatment. High-throughput screening of selective inhibitors of CSC growth and survival have identified the potassium ionophore salinomycin as a promising drug candidate, although its mechanism of action is unclear. ${ }^{21}$ The potential of a synthetic chloride channel to regulate cell membrane potential has also been reported. ${ }^{22}$

Here we report the biological activity of transmembrane anion transporters inspired in the structure of marine metabolites tambjamines. We demonstrate how these molecules induce $\mathrm{pHi}$ acidification and cytotoxicity related to their anion transport abilities. We also show how the facilitated transport activity triggers plasma membrane hyperpolarization leading to cancer stem cell differentiation and effective elimination of this cell population.

\section{RESULTS AND DISCUSSION}

Synthesis and anion transport through lipid bilayers. Compounds 1-3 (Chart 1) were selected for this study. These compounds are inspired in the structure of marine secondary metabolites tambjamines. ${ }^{23}$ They are readily prepared by acid catalyzed condensation of 5-(1H-indol-2-yl)-3-methoxy-1H- pyrrole-2-carbaldehyde and the appropriate amine. These compounds are isolated as stable yellow-orange solids in good yields as hydrochloride salts and fully characterized (see supporting information for details). The spectroscopic data evidenced the strong hydrogen bond interaction between these compounds and the chloride anion. These interactions are also evident in the solid state structures of compounds $\mathbf{1}$ and $\mathbf{2}$ (Chart 1). The two heterocycles and the enamine moiety are essentially coplanar. A chloride anion is found interacting with the pyrrole and enamine $\mathrm{N}-\mathrm{H}$ groups whereas the indole moiety is found rotated 180 and interacting with a second chloride anion. A conformational analysis of these molecules both in solution and computationally is provided in the supplementary information. In their preferred conformation these molecules bind the anion through the hydrogen bond cleft involving the three N-H groups of the molecule.

The chloride anion binding ability of $\mathbf{1}$ and $\mathbf{2}$ was explored by means of ${ }^{1} \mathrm{H}$ NMR titration experiments using perchlorate salts of these derivatives and tetrabutylammoniun chloride in DMSO- $d_{6}$. Under these conditions chloride readily replace the less coordinating perchlorate anion and an association constants could be calculated at 3301 and $3778 \mathrm{M}^{-1}$ for $\mathbf{1 . H C l O} 4$ and $2 . \mathrm{HClO}_{4}$ respectively. Treatment of DMSO- $d_{6}$ solutions of 1. $\mathrm{HClO}_{4}$ and $2 . \mathrm{HClO}_{4}$ with tetraethylammonium bicarbonate resulted in deprotonation of the compounds. Lack of solubility prevented the study of these processes in pure water. Nevetheless, the apparent pKa values of $\mathbf{1}$ and $\mathbf{2}$ were calculated in DMSO:water 1:1 mixtures at 9.64 and 9.62. This result as well as computational studies suggested that deprotonation is not likely to occur under physiological conditions (See supplementary Figures S89-S92). On the other hand, in their neutral form, these derivatives are also able to bind anions under these conditions albeit with lower affinity (See supplementary Figures S49-S53).

The anion transport properties of 1-3 were assayed in 1palmitoyl-2-oleoyl-sn-glycero-3-phosphocholine (POPC) vesicles using a chloride selective electrode to evaluate the chloride efflux promoted by these compounds. Thus, liposomes loaded with $\mathrm{NaCl}$ were suspended in an isotonic, chloride free external medium. Chloride release promoted by 1-3 
was monitored over time and at the end of the experiment the vesicles were lysed by the addition of detergent, being the final electrode reading used as $100 \%$ release of chloride. Repeating these assays in the presence of variable amounts of compound allowed Hill analyses and calculation of $\mathrm{EC}_{50}$ values (the concentration of carrier needed to achieve the release of $50 \%$ of encapsulated chloride) for comparative purposes (Table 1). Compounds $\mathbf{1}$ and $\mathbf{2}$ proved to be extremely active transmembrane transporters, whereas compound $\mathbf{3}$ displayed modest activity as anion carrier. This difference in transmembrane transport activity is likely due to the significantly lower calculated lipophilicity of $\mathbf{3}$ with respect to $\mathbf{1}$ and $\mathbf{2}$ (See table S3). The key role of lipophilicity in the design of effective anion transporters has been studied in several families of compounds including tambjamine analogs. ${ }^{24,25}$

Table 1. Transport activities for compounds 1-3.

\begin{tabular}{cccc}
\hline \multirow{2}{*}{ Compound } & \multicolumn{2}{c}{$\mathrm{EC}_{50} \mathrm{NO}_{3}{ }^{-} / \mathrm{Cl}^{-\mathrm{a}}$} & $\begin{array}{c}\text { Hill } \\
\text { parameter }\end{array}$ \\
\cline { 2 - 3 } & $(\mu \mathrm{M})$ & $(\%)$ & $1.12 \pm 0.10$ \\
$\mathbf{2}$ & $0.101 \pm 0.007$ & $0.020 \pm 0.001$ & $1.17 \pm 0.14$ \\
$\mathbf{3}$ & $0.041 \pm 0.003$ & $0.008 \pm 0.001$ & Hill \\
\hline & $17.212 \pm 1.172$ & $3.442 \pm 0.234$ & $1.13 \pm 0.10$ \\
\hline \multirow{2}{c}{$\mathrm{EC}_{50} \mathrm{HCO}_{3}{ }^{-} / \mathrm{Cl}^{-\mathrm{b}}$} & parameter \\
\hline $\mathbf{1}$ & $(\mu \mathrm{M})$ & $(\%)$ & $1.16 \pm 0.15$ \\
$\mathbf{3}$ & $0.243 \pm 0.023$ & $0.048 \pm 0.005$ & $1.49 \pm 0.07$ \\
& $0.137 \pm 0.004$ & $0.027 \pm 0.001$ & n.d.
\end{tabular}

${ }^{a}$ vesicles loaded with $489 \mathrm{mM} \mathrm{NaCl}$ dispersed in $489 \mathrm{mM} \mathrm{NaNO}_{3}$ (5 mM phosphate buffer, pH 7.2). ${ }^{b}$ vesicles loaded with $451 \mathrm{mM}$ $\mathrm{NaCl}$ dispersed in $150 \mathrm{mM} \mathrm{Na}_{2} \mathrm{SO}_{4}(20 \mathrm{mM}$ phosphate buffer, $\mathrm{pH}$ 7.2) upon addition of a $\mathrm{NaHCO}_{3}$ pulse to make the extravesicular bicarbonate concentration $40 \mathrm{mM}$. ${ }^{\mathrm{c}}$ not determined (carrier loadings over $5 \%$ promoted less than $50 \%$ chloride efflux).

Compounds $\mathbf{1}$ and $\mathbf{2}$ were selected as their calculated lipophilicity matched the optimal $\log P$ range for these compounds in order to maximize their transport activity. Compound 3 was predicted to display very limited activity. The experimental results fully supported this hypothesis. The nature of the external anion impacted dramatically in the rate of chloride efflux promoted by these compounds (See supplementary Figures S122-S123). Both a Hill parameter close to one and the differences in $\mathrm{EC}_{50}$ values found when the chloride efflux is measured in the presence of nitrate, bicarbonate or sulfate suggested that these compounds function as discrete carriers promoting anion exchange through the lipid bilayer. The relatively higher hydrophilicity of bicarbonate compared with nitrate resulted in lower chloride efflux at higher carrier loadings. This was unsurprising as anion exchange has already been reported as the main mechanism accounting for the activity as anion carriers for tambjamine derivatives. Experiments using different metal chlorides such as $\mathrm{KCl}, \mathrm{RbCl}$ and $\mathrm{CsCl}$ were also performed and no significant differences were observed (Supplementary Figures S124-S126). Thus influence of the metal cation in the transmembrane transport event can be ruled out. Carboxyfluorescein leakage assays also rule out the possibility of these compounds functioning as membrane disruptors promoting unspecific chloride leakage (Supplementary Figures S136). This set of assays demonstrated that $\mathbf{1}$ and $\mathbf{2}$ are very efficient transmembrane transporters. Compound $\mathbf{3}$ represents an adequate control molecule, being structurally very similar to $\mathbf{1}$ and $\mathbf{2}$ yet displaying significantly lower level of transmembrane transport activity (Table 1).

Anionophores induce intracellular $\mathbf{p H}$ changes and cellular toxicity. In order to evaluate the ability of anionophores 1 - 3 to modulate intracellular $\mathrm{pH}$ (pHi), first vital staining with acridine orange (AO) was used. When this cellpermeable dye accumulates in acidic compartments, such as lysosomes, it shows a characteristic orange fluorescence emission, while it emits green fluorescence at higher $\mathrm{pH}$, such as in the cytosol. Human lung adenocarcinoma (A549) cells were stained with $\mathrm{AO}$ and typical granular orange fluorescence was observed, corresponding to cellular acidic compartments (Figure 2a). Treatment with active anion transporters $\mathbf{1}$ and $\mathbf{2}$ induced complete loss of orange fluorescence whereas treatment with compound $\mathbf{3}$ did not modify AO emission, compared to non-treated cells. These results evidenced an increase in the $\mathrm{pH}$ of acidic organelles upon treatment with the active anion transporters $\mathbf{1}$ and $\mathbf{2}$, as opposite to control compound $\mathbf{3}$.

We were also interested in studying variations in cytoplasmic $\mathrm{pH}$ levels. This parameter has been claimed to modulate cell proliferation and apoptosis. ${ }^{26}$ Therefore it could be more relevant to gain insight into the mechanisms accounting for the cytotoxicity of these compounds. Thus, changes in $\mathrm{pHi}$ of A549 cells after treatment with $\mathbf{1}$ - $\mathbf{3}$ were quantified using the $\mathrm{pH}$-sensitive fluorescent dye SNARF®-1. In its ester form, 5-(and-6)-carboxy seminaphthorhodafluor-1acetoxymethylester (SNARF-1-AM) can diffuse across the cellular membrane into the cytoplasm. Hydrolization of this compound by cellular esterases yield the cell-impermeable fluorescent dye carboxy-SNARF-1. This dye can be used for quantitative determinations of pHi because it exhibits a significant $\mathrm{pH}$-dependent emission shift in the appropriate range. First, fluorescent signal ratios at $576 \mathrm{~nm}$ and $664 \mathrm{~nm}$ were determined under different $\mathrm{pH}$ conditions, which allowed us constructing a calibration curve. Then, fluorescence of SNARF-1 was measured in A549 cells. Upon treatment with $10 \mu \mathrm{M}$ concentration of active anionophores $\mathbf{1}$ and $\mathbf{2}$, pHi dropped significantly. A lowering of $0.33 \pm 0.10$ and $0.70 \pm$ $0.22 \mathrm{pH}$ units was measured for compound 1 and 2 respectively after $1 \mathrm{~h}$ (Figure 2b). Such change of pHi is known to be sufficient to trigger apoptotic processes in cells. ${ }^{26}$ Under these conditions, compound 3 only induced minor changes of $\mathrm{pHi}$ inducing an increase of $0.02 \pm 0.14 \mathrm{pH}$ units. These results are in agreement with the involvement of the transmembrane transport activity in the lowering of $\mathrm{pHi}$ observed.

To assess whether chloride transport participated in the cytotoxic effect exhibited by $\mathbf{1}$ and $\mathbf{2}$, cell viability was measured in A549 cells resuspended in Hank's balanced salt solution (HBSS) either containing chloride or without this anion (Figure 2c, 2d). Moderate yet significant differences between cell viability in both buffers upon treatment with $\mathbf{1}$ and $\mathbf{2 w e r e}$ observed, with reduced cytotoxicity in absence of chloride. Under these conditions, calculated inhibitory concentration 50 (IC50) values in the presence of chloride dropped to $8.8 \mu \mathrm{M}$ and $9.6 \mu \mathrm{M}$ from the calculated $12.4 \mu \mathrm{M}$ and $12.11 \mu \mathrm{M}$ in HBSS without chloride for compounds 1 and 2 respectively. This result as well as the reduced toxicity of inactive transporter 3 (See supplementary Figure S136) again supported the involvement of anion transport in the cytotoxic effect exerted by $\mathbf{1}$ and $\mathbf{2}$. 
a)

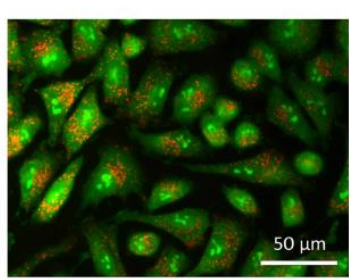

CPD $110 \mu \mathrm{M}$

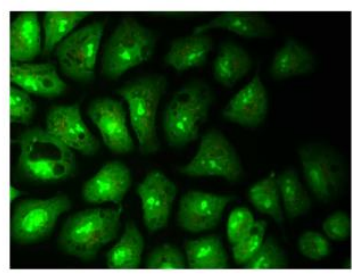

CPD $210 \mu \mathrm{M}$

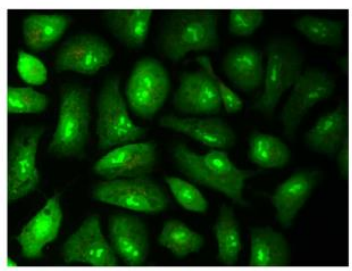

CPD $310 \mu \mathrm{M}$

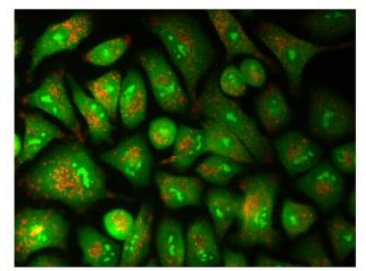

b)

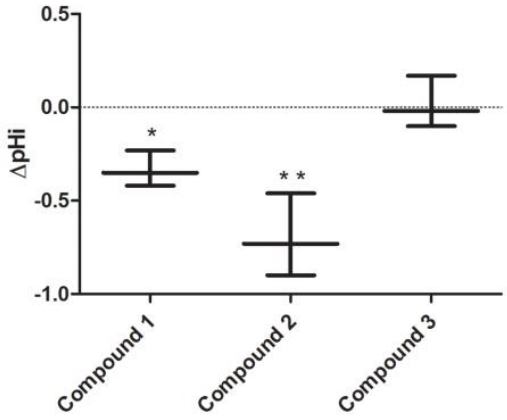

c)

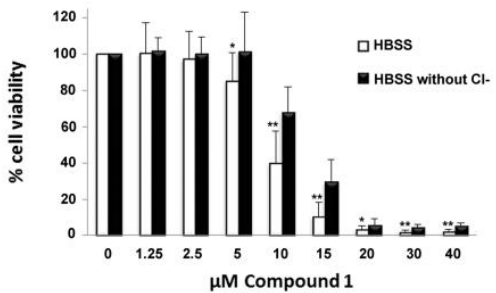

d)

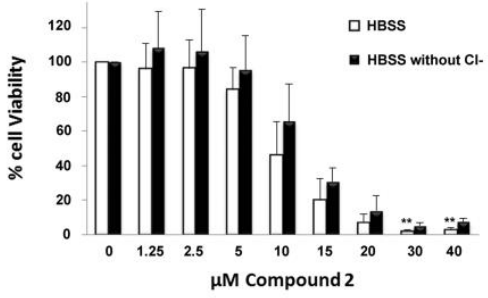

Figure 2. Transmembrane anion transport impact intracellular $\mathrm{pH}(\mathrm{pHi})$ levels and reduce cell viability. (a) Acridine orange staining on human lung adenocarcinoma (A549) cells. From left to right: Untreated (control) cells; cells treated with compound 1; compound 2 and compound $3(10 \mu \mathrm{M})$. Disappearance of orange fluorescence due to basification of acidic organelles is evident upon treatment with active anionophores. (b) pHi measurements using SNARF-1 staining. A significant decrease in pHi is observed after treatment with $10 \mu \mathrm{M}$ of compound 1 or 2 . $* \mathrm{p}<0.05 ; * * \mathrm{p}<0.01$. (c), (d), Cell viability after treatment with compound $\mathbf{1}$ and $\mathbf{2}$ in the presence (HBSS) or absence (HBSS without $\mathrm{Cl}^{-}$) of chloride ion. Higher cytotoxicity is observed in the presence of chloride ion. $* \mathrm{p}<0.05 ; * * \mathrm{p}<0.01$.

Membrane potential changes in liposomes and voltage changes in single A549 cells. We decided to explore the potential of these compounds to induce changes in the membrane polarization. We first explore this possibility in model liposomes. Thus, membrane potential sensitive dye safranin $\mathrm{O}$ was used. The fluorescence of this compound is affected by changes in membrane potential. ${ }^{27}$ POPC vesicles containing $\mathrm{NaCl}$ were suspended in a $\mathrm{Na}_{2} \mathrm{SO}_{4}$ solution. As demonstrated using chloride selective electrode assays, compounds $\mathbf{1}$ - $\mathbf{3}$ are unable to promote sulfate transport (See Figure S119, S120) and under these conditions only chloride permeation can occur. Addition of active transporters $\mathbf{1}$ and $\mathbf{2}$ at $0.1 \%$ molar carrier:lipid resulted in a marked decrease in safranin $\mathrm{O}$ fluorescence (Figure 3b). Control experiments using the essentially inactive transporter 3 or DMSO resulted in no significant change of fluorescence. These results are consistent with a decrease of the membrane potential induced by $\mathbf{1}$ and $\mathbf{2}$. Likewise, little change in safranin $O$ fluorescence was observed when these experiments were carried out with no chloride electrochemical potential (Figure 3a).

We next aimed to assess the ability of anion transporters to induce voltage changes in A549 cells. A549 cells were transfected with the VSFP2.32 genetically encoded voltage indicator, which permits monitoring membrane voltage changes by recording changes in FRET efficacy between a pair of fluorescent proteins. ${ }^{28,29}$ To determine the voltage range within VSFP2.32 reports, voltage changes in A549 cells, VSFP2.32 expressing cells, were patch-clamped, and a voltage ramp (from 130 to $-170 \mathrm{mV}$ ) was applied. A progressive decrease in FRET was observed as the cell membrane was hyperpolarized to negative voltages from $-30 \mathrm{mV}$ and down to $-170 \mathrm{mV}$ (Figure $3 \mathrm{c})$. We next evaluated the effects of compounds 1-3 on membrane voltage. The superfusion of transporter $\mathbf{1}$ induced a robust decrease in the FRET signal (Figure 3d). The decrease in the FRET signal indicates that treatment with this compound hyperpolarized A549 cells. These cells normally exhibit a resting $\mathrm{Vm}$ close to $0 \mathrm{mV}$ that upon facilitated influx of anions shifts to more negative values. Similar to the transporter 1, transporter 2 also produced a decrease on FRET signal (Supplementary Figure S141), although with slightly different kinetics. Thus, transporter $\mathbf{1}$ had a higher magnitude of the signal $(0.18 \pm 0.03$ vs $0.15 \pm 0.02)$ and faster $\tau$ time constant $(5.16 \pm 0.79$ vs $7.65 \pm 0.58$ s) than transporter 2 . Finally, we attempted to demonstrate that the critical feature of these compounds in order to induce $\mathrm{Vm}$ changes was their anion transport abilities. Thus transporter $\mathbf{3}$, possessing much reduced potency as transmembrane anion transporter, was then assayed in the FRET illumination protocol, in order to monitor possible voltage alterations (Figure 3e). This compound induced significantly lower decreases in the FRET signal $(0.03 \pm$ 0.01 ) than transporter $\mathbf{1}$ and $\mathbf{2}$, thus demonstrating again that hyperpolarization of the cell membrane was induced as a result of the transmembrane transport facilitated by active anion transporters.

Cytotoxicity of anion transporters. The effects of anion transporters 1 - 3 on A549 cancer cells as well as cell lines derived from primary tumors from two non-small cell lung cancer patients (FIS302 and FIS303) were examined. We were interested in determine the cytotoxicity against both differentiated and cancer stem cells (CSCs). Thus cells were cultured in 
(a)

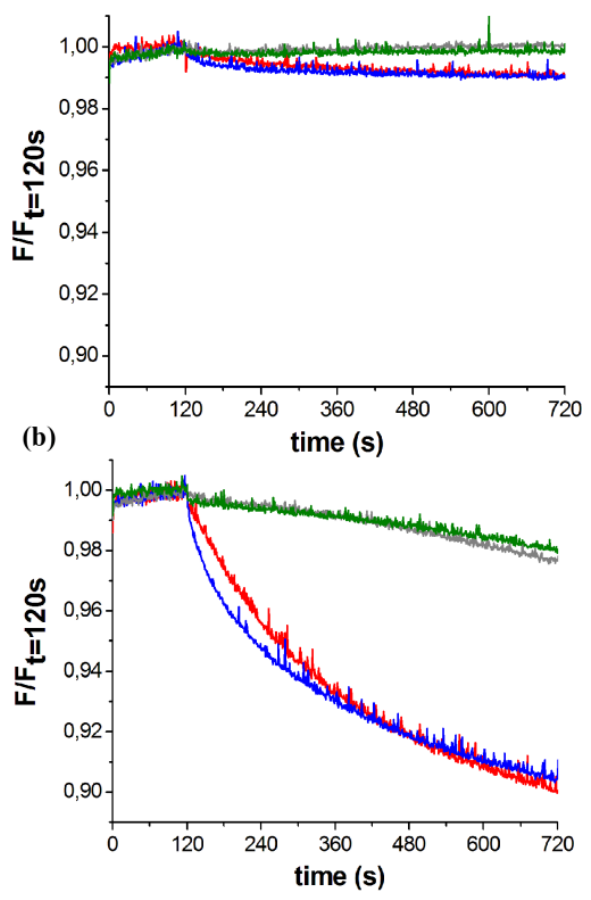

(c)
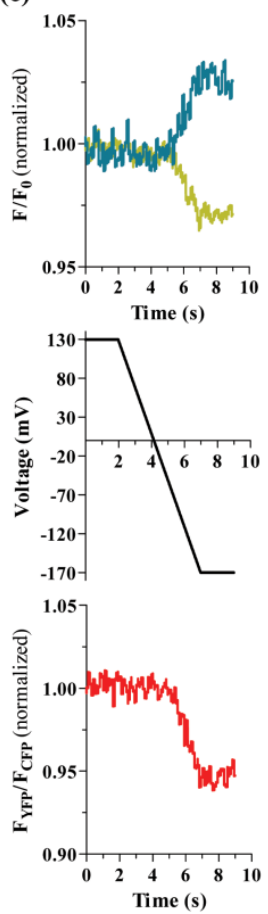

(d)
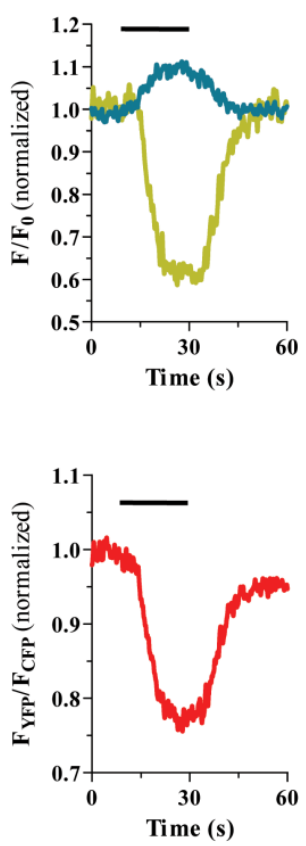

(e)
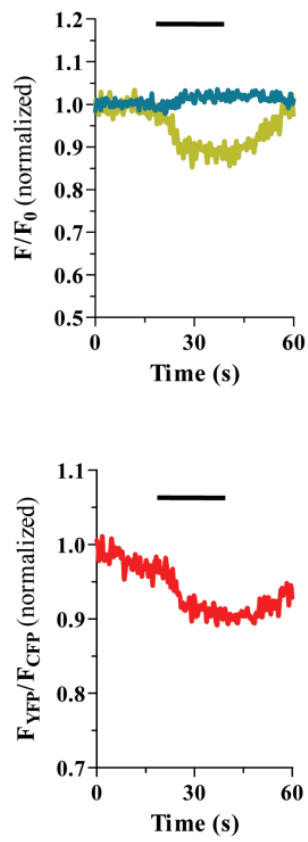

Figure 3. Transmembrane anion transporters induce changes in membrane potential. (a)-(b) changes in safranin $\mathrm{O}$ fluorescence. The anion carrier $(0.1$ molar\% with respect to phospholipids) was added at $\mathrm{t}=120 \mathrm{~s}$, after that the experiments were monitored over $600 \mathrm{~s}$. Each trace represents the average of three trials. Compound 1 red trace, 2 blue, 3 grey, control DMSO green. (a) Vesicles loaded with $\mathrm{NaCl}$ (28.8 $\mathrm{mM}$ $\mathrm{NaCl}$, and $5 \mathrm{mM}$ phosphate buffer, $\mathrm{pH} 7.2$, ionic strength $40 \mathrm{mM})$ were immersed in $\mathrm{NaCl}(28.8 \mathrm{mM} \mathrm{NaCl}$, and $5 \mathrm{mM}$ phosphate buffer, $\mathrm{pH} 7.2$, ionic strength $40 \mathrm{mM}$ and Safranin $\mathrm{O} 0.2 \mu \mathrm{M})$. (b) Vesicles loaded with $\mathrm{NaCl}(28.8 \mathrm{mM} \mathrm{NaCl}$, and $5 \mathrm{mM}$ phosphate buffer, pH 7.2 , ionic strength $40 \mathrm{mM}$ ) were immersed in $\mathrm{Na}_{2} \mathrm{SO}_{4}\left(9.6 \mathrm{mM} \mathrm{Na}_{2} \mathrm{SO}_{4}, 5 \mathrm{mM}\right.$ phosphate buffer pH 7.2 , ionic strength $40 \mathrm{mM}$ and Safranin O $0.2 \mu \mathrm{M}$ ). (c)-(e) FRET changes of the VSFP2.32 voltage biosensor. (c) a voltage ramp (shown in the middle panel, from 130 to -170 $\mathrm{mV}),(\mathrm{d})$, transporter 1 and (e), transporter 3. Shown are the time-resolved changes in mCerulean and Citrine fluorescence emission signals in single A549 cells expressing the VSFP 2.32. The emission intensities of mCerulean (blue trace), Citrine (yellow trace) and the ratio FCitrine/FmCerulean (red trace) were recorded simultaneously. Traces are representative of five separate experiments.

adherence or as spheroids and were treated $10 \mu \mathrm{M}$ concentrations of each of the selected compounds. The results are shown in Figure 4. For all cell lines, viability after $24 \mathrm{~h}$ was significantly diminished in A549, FIS302 and FIS303 spheroids compared with the cells grown in monolayer by compounds $1(\mathrm{p}=0.012, \mathrm{p}<0.0001$ and $\mathrm{p}<0.0001$, respectively $)$ and $2(p=0.018, p=0.004$ and $p<0.0001$, respectively $)$. On theother hand, treatment with the much less active transporter $\mathbf{3}$ did not significantly affect the viability of the treated cells. For comparative purposes doxorubicin, a classic chemotherapeutic drug, was also included in this study. These results indicate that active anion transporters selectively inhibited CSC viability. Similar results were also observed in a variety of other lung cancer cells lines (H1650, H1993, PC9) (supplementary Figure S137).

Anion transporters affect expression of cancer stem cell (CSC) surface markers. Stemness properties of CSCs have been associated with the expression of several cell surface markers. ${ }^{30}$ Thus, the effect of compounds $\mathbf{1}-\mathbf{3}$ on the expression of lung stem cell surface markers of A549 CSCs as well as FIS302 and FIS303, two patient-derived CSCs, was assessed by immunofluorescence and flow cytometry. Since cell viability in the presence of $10 \mu \mathrm{M}$ concentrations of compounds $\mathbf{1}$ and $\mathbf{2}$ for $24 \mathrm{~h}$ is very low, cells were incubated with $2.5 \mu \mathrm{M}$ of each compound in order to analyze potential alterations of lung stem cell surface markers before cell death.

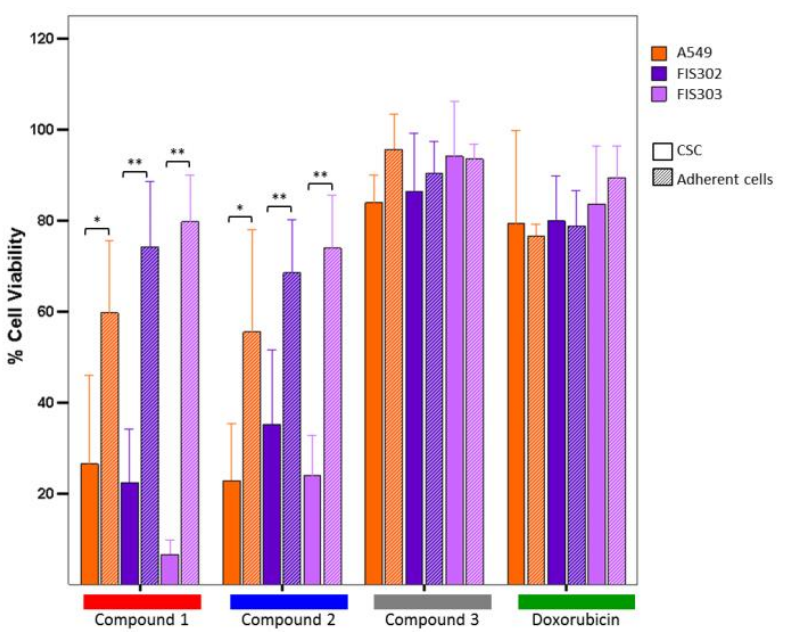

Figure 4. Cytotoxicity assays on cancer stem cells and adherent cells. A549, FIS302 and FIS303 adherent and CSCs. Cells were treated with $10 \mu \mathrm{M}$ of each compound $(\mathbf{1}, \mathbf{2}$ or $\mathbf{3})$. Doxorubicin $(10 \mu \mathrm{M})$ was used as control. Mean and standard deviations of three independent experiments are shown $\left(* \mathrm{p}<0.05,{ }^{*} \mathrm{p}<0.01\right)$. 


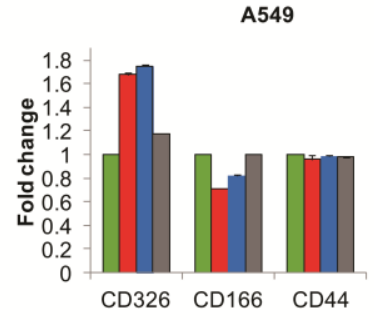

b)

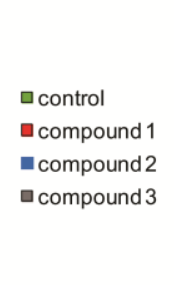

FIS302

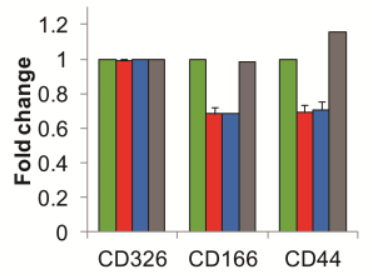

c)

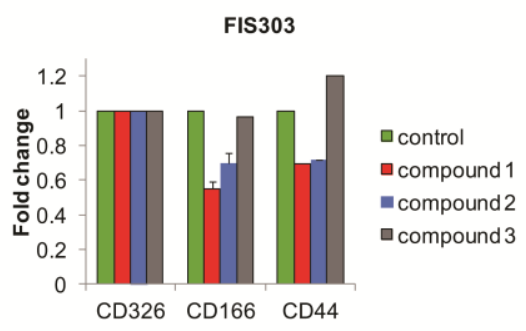

Figure 5. Compounds 1 and 2 affect expression of cancer stem cell surface markers. (a) A549 (b), FIS302 (c), FIS303 CSCs. CSCs were treated with $2.5 \mu \mathrm{M}$ compound $\mathbf{1 , 2}$ or $\mathbf{3}$ for $24 \mathrm{~h}$ and the expression of CD326 (EpCAM), CD166 and CD44 was analyzed by flow cytometry. The expression of these markers was relativized to those in control cells. Data represent the average of three independent experiments. Bars correspond to standard deviations.
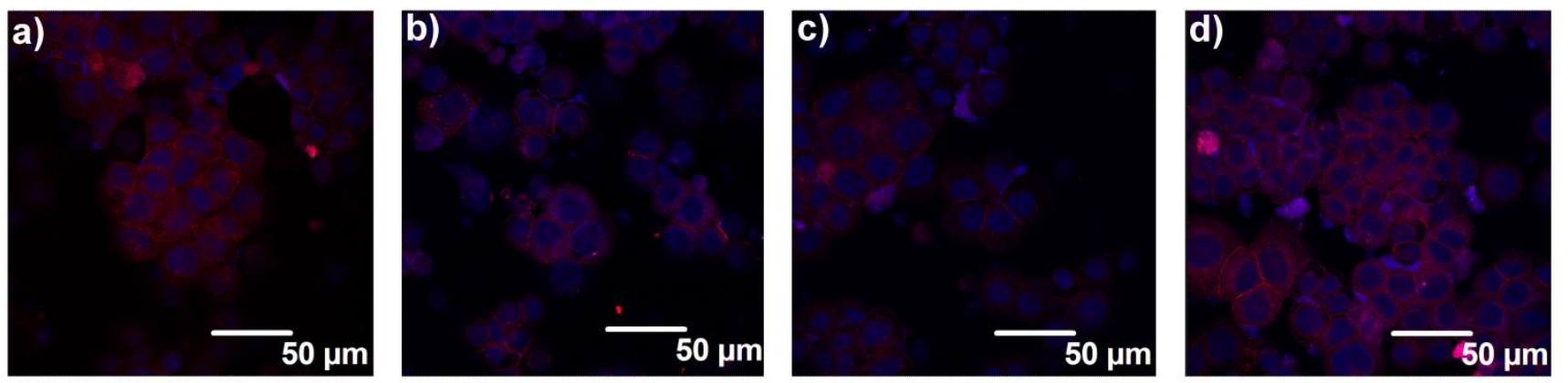

Figure 6. Compounds 1 and 2 induce tumor CSCs spheres disaggregation. E-cadherine expression in FIS302 tumor spheres growing in suspension assessed by immunofluorescence. Merged projection of both cell nuclei with pattern of DAPI-staining (blue channel) and Ecadherine staining (red channel). Scale bar is $50 \mu \mathrm{m}$. (a) untreated control cells. (b) CSCs treated with compound 1. (c) CSCs treated with compound 2. (d) CSCs treated with compound 3.

Incubation of A549 cells with $2.5 \mu \mathrm{M}$ of 1 and 2 for $24 \mathrm{~h}$ led to an increase of the epithelial cell adhesion molecule CD326(EpCAM) expression by 70\%, and downregulation of CD166 by 20\% compared to control cells treated with DMSO. No significant changes were observed in the expression of CD44. Compound $\mathbf{3}$ induced no significant changes in the three surface markers studied here compared to control cells (Figure 5a). FIS302 patient-derived CSCs treated with compounds 1 and 2 showed a 30\% decrease in CD166 and CD44expression (Figure 5b). No significant changes were observed in the expression of EpCAM, CD44 and CD166 in the cells treated with compound 3 (Figure 5b). FIS303 patientderived CSCs treated with compound 1 showed a 50\% reduction in CD166 expression. The treatment with compound 2 led to a $30 \%$ reduction in CD166 expression. Both compounds $\mathbf{1}$ and 2 led to a $30 \%$ decrease in CD44 expression (Figure 5c). Similarly to FIS302 cells, no significant changes were observed in the expression of EpCAM, CD44 and CD166 in cells treated with compound 3 (Figure $5 \mathrm{c}$ ). Taken together, downregulation of CD166 and upregulation of CD326 (EpCAM) populations in A549 CSCs, and downregulation of CD166 and CD44 populations in FIS302 and FIS303 patient-derived CSC, suggest that the CSCs properties of A549, FIS302 and FIS303 cells are affected by compounds $\mathbf{1}$ and $\mathbf{2}$. Further evidences came from inmunofluorescence assays (Figure 6). Thus, the size of the tumor spheres decreases when treated with compounds $\mathbf{1}$ and $\mathbf{2}$ compared to spheres treated with compound $\mathbf{3}$ or DMSO, and disaggregation was evident (Figure 6).

\section{CONCLUSIONS}

In summary, we have studied two highly active transmembrane anion transporters $\mathbf{1}$ and $\mathbf{2}$ capable of facilitating transmembrane transport of chloride and bicarbonate in model liposomes. These compounds induce $\mathrm{pHi}$ acidification and hyperpolarization of cellular membranes. We have shown that this combined effect led to loss of stemness characteristics of CSCs and selective elimination of this cell population. The fact that the structurally related yet poorly effective transporter 3 did not exert any of these effects led us to conclude that facilitated anion transport plays a crucial role in the biological action of these compounds. We conclude that small molecule anionophores could represent valuable chemotherapeutics for the manipulation of CSCs behavior.

\section{ASSOCIATED CONTENT}

\section{Supporting Information.}

Syntheses and characterization data, computational studies and descriptions of liposome-based anion transport assays and membrane potential assays. Crystallographic information. Details on cell lines and culture conditions, acridine orange and SNARF-1 staining, cell viability assays, microscopic FRET measurements, tumor cell preparation, cancer stem cells, flow cytometry analysis. This material is available free of charge via the Internet at http://pubs.acs.org.

\section{AUTHOR INFORMATION \\ Corresponding Authors \\ *rquesada@ubu.es \\ *rperez@ub.edu}




\section{Notes}

V. S.-C. and P. M.-M. contributed equally to this work. The authors declare no competing financial interest.

\section{ACKNOWLEDGMENT}

This work was supported by grants from the Spanish government and the EU (FIS PI13/00089, FIS PI12/02838, FIS PI12/00956 and RD12/0036/0025), a grant from La Marató de TV3 Foundation (20132730), a grant from SEPAR (17/2014), Consejería de Educación de la Junta de Castilla y León (Project BU340U13), Ministerio de Economía y competitividad/Instituto de Salud Carlos III (SAF2014-55700-P) and ICREA Academia-2010. E.H. thanks the Junta de Castilla y León (Consejería de Educación) and the Fondo Social Europeo for a PIRTU contract. The authors thank Benjamín Torrejón and Esther Castaño from CCiT (Centres Científics i Tecnològics, Campus de Bellvitge, Universitat de Barcelona), Sandra Tejedor (Centro de Investigación Príncipe Felipe), Luís Korrodi-Gregório (UB), and Andrea Sancho (UBU) for their technical support.

\section{REFERENCES}

(1) Overington, J. P.; Al-Lazikani, B.; Hopkins, A. L. Nat. Rev. Drug Discov. 2006, 5, 993.

(2) (a) Gokel, G. W.; Negin, S. Acc. Chem. Res. 2013, 46, 2824. (b) Matile, S.; Fyles, T. Acc. Chem. Res. 2013, 46, 2741. (c) Otis, F.; Auger, Mi; Voyer, N. Acc. Chem. Res. 2013, 46, 2934.

(3) (a) Sakai, N.; Matile, S. Langmuir 2013, 29, 9031. (b) Alfonso, I.; Quesada R. Chem. Sci. 2013, 4, 3009.

(4) (a) Davis, A. P.; Sheppard, D. N.; Smith, B. D. Chem. Soc. Rev. 2007, 36, 348. (b) Davis, J. T.; Okunola, O.; Quesada, R. Chem. Soc. Rev. 2010, 39, 3843. (c) Busschaert, N.; Gale, P. A. Angew. Chem. Int. Ed. 2013, 52, 1374.

(5) Vargas Jentzsch, A.; Emery, D.; Mareda, J.; Nayak, S. K.; Metrangolo, P.; Resnati, G.; Sakai, N.; Matile, S. Nat. Commun. 2012, 3,905 .

(6) Santacroce, P. V.; Okunola, O. A.; Zavalij, P. Y.; Davis, J. T. Chem. Commun. 2006, 3246.

(7) (a) Moore, S. J.; Wenzel, M.; Light, M. E.; Morley, R.; Bradberry, S. J.; Gómez-Iglesias, P.; Soto-Cerrato, V.; Pérez-Tomás, R.; Gale, P. A. Chem. Sci. 2012, 3, 2501. (b) Gale, P. A.; Tong, C. C.; Haynes, C. J. E.; Adeosun, O.; Gross, D. E.; Karnas, E.; Sedenberg, E. M.; Quesada, R.; Sessler, J. L. J. Am. Chem. Soc. 2010, 132, 3240. (c) Harrel, W. A., Jr.; Bergmeyer, M. L.; Zavalij, P. Y.; Davis, J. T. Chem. Commun. 2010, 46, 3950. (c) Martí, I.; Rubio, J.; Bolte, M.; Burguete, M. I.; Vicent, C.; Quesada, R.; Alfonso I.; Luis, S. V. Chem. Eur. J. 2012, 18, 16728.

(8) (a) Cooper, J. A.; Street, S. T.; Davis, A. P. Angew. Chem. Int. Ed. 2014, 53, 5609. (b) Elie, C. R.; Noujeim, N.; Pardin C.; Schmitzer. A. R. Chem.Commun. 2011, 47, 1788.

(9) (a) Estelle, M.; Soumya, R.; Alison, T.; Jeffery, D. Org. Biomol. Chem. 2014, 12, 7515. (b) Busschaert, N.; Karagiannidis, L. E.; Wenzel, M.; Haynes, C. J. E.; Wells, N. J.; Young, P. G.; Makuc, D.; Plavec, J.; Jolliffe, K. A.; Gale, P. A. Chem. Sci. 2014, 5, 1118.

(10) (a) Park, E. B.; Jeong, K. S. Chem. Commun. 2015, 51, 9197. (b) Valkenier, H.; Judd, L. W.; Li, H.; Hussain, S.; Sheppard, D. N.; Davis, A. P. J. Am. Chem. Soc. 2014, 136, 12507.

(11) Sessler, J. L.; Eller, L. R.; Cho, W. S.; Nicolaou, S.; Aguilar, A.; Lee, J. T.; Lynch, V. M.; Magda, D. J. Angew. Chem. Int. Ed. $\mathbf{2 0 0 5}, 44,5989$.

(12) (a) de Greñu, B. D.; Hernandez, P. I.; Espona, M.; Quiñonero, D.; Light, M. E.; Torroba, T.; Pérez-Tomás R.; Quesada. R. Chem. Eur. J. 2011, 17, 14074. (b) Gale, P. A.; Perez-Tomas, R.; Quesada, R. Acc. Chem. Res. 2013, 46, 2801. (c)

(13) Ko, S. K.; Kim, S. K.; Share, A.; Lynch, V. M.; Park, J.; Namkung, W.; Van Rossom, W.; Busschaert, N.; Gale, P. A.; Sessler, J. L.; Shin, I. Nat. Chem. 2014, 6, 885.

(14) (a) Litan, A.; Langhans, S. A. Front. Cell. Neurosci. 2015, 9 , 86. (b) DiGiammarino, E. L.; Lee, A. S.; Cadwell, C.; Zhang, W.;
Bothner, B.; Ribeiro, R. C.; Zambetti, G.; Kriwacki, R. W. Nat. Struct. Biol. 2002, 9, 12 .

(15) (a) Webb, B. A.; Chimenti, M.; Jacobson, M. P.; Barber, D. L. Nat. Rev. Cancer 2011, 11, 671. (b) Gillies, R. J.; Raghunand, N.; Karczmar, G. S.; Bhujwalla, Z. M. J. Magn. Reson. Imaging 2002, 16, 430.

(16) (a) Damaghi, M.; Wojtkowiak, J. W.; Gillies, R. J. Front. Physiol. 2013, 4, 370. (b) Lang, F.; Stournaras, C. Phil. Trans. R. Soc. B 2014, 369, 20130108. (c) McCarty, M. F.; Whitaker, J. Altern. Med. Rev. 2010, 15, 264.

(17) (a) Sundelacruz, S.; Levin, M.; Kaplan, D. L. Stem Cell Rev. and Rep. 2009, 5, 231. (b) Wonderlin, W. F.; Woodfork, K. A.; Strobl, J. S. J. Cell Physiol. 1995, 165, 177. (c) Sundelacruz, S.; Levin, M.; Kaplan, D. L. PLoS One 2008, 3, e3737.

(18) (a) Valent, P.; Bonnet, D.; De Maria, R.; Lapidot, T.; Copland, M.; Melo, J. V.; Chomienne, C.; Ishikawa, F.; Schuringa, J. J.; Stassi, G.; Huntly, B.; Herrmann, H.; Soulier, J.; Roesch, A.; Schuurhuis, G. J.; Wohrer, S.; Arock, M.; Zuber, J.; Cerny-Reiterer, S.; Johnsen, H. E.; Andreeff, M.; Eaves, C. Nat. Rev. Cancer 2012, 12, 767. (b) Reya, T.; Morrison, S. J.; Clarke, M. F.; Weissman, I. L. Nature 2001, 414, 105. (c) Singh, A.; Settleman, J. Oncogene 2010, 29, 4741.

(19) Yang, M.; Brackenbury, W. J. Front. Physiol. 2013, 4, 185.

(20) Vidal, S. J.; Rodriguez-Bravo, V.; Galsky, M.; Cordon-Cardo, C.; Domingo-Domenech, J. Oncogene 2014, 33, 4451.

(21) Gupta, P. B.; Onder, T. T.; Jiang, G.; Tao, K.; Kuperwasser, C.; Weinberg, R. A.; Lander, E. S. Cell 2009, 138, 645.

(22) Li, X.; Shen, B.; Yao, X. Q.; Yang, D. J. Am. Chem. Soc. 2009, 131, 13676.

(23) Carte, B.; Faulkner, D. J. J. Org. Chem. 1983, 48, 2314.

(24) (a) Saggiomo, V.; Otto, S.; Marques, I.; Felix, V.; Torroba, T.; Quesada, R. Chem. Commun. 2012, 48, 5274. (b) Valkenier, H.; Haynes, C. J. E.; Herniman, J.; Gale, P. A.; Davis, A. P. Chem. Sci. 2014, 5, 1128.

(25) Busschaert, N.; Bradberry, S. J.; Wenzel, M.; Haynes, C. J. E.; Hiscock, J. R.; Kirby, I. L.; Karagiannidis, L. E.; Moore, S. J.; Wells, N. J.; Herniman, J.; Langley, G. J.; Horton, P. N.; Light, M. E.; Marques, I.; Costa, P. J.; Félix, V.; Frey, J. G.; Gale, P. A. Chem. Sci. 2013, 4, 3036.

(26) Lagadic-Gossmann, D.; Huc, L.; Lecureur, V. Cell Death Differ. 2004, 11, 953.

(27) Sidorov, V.; Kotch, F. W.; Kuebler, J. L.; Lam, Y. F.; Davis, J. T. J. Am. Chem. Soc. 2003, 125, 2840.

(28) Akemann, W.; Mutoh, H.; Perron, A.; Rossier, J.; Knopfel, T. Nat. Methods 2010, 7, 643.

(29) Akemann, W.; Song, C.; Mutoh, H.; Knopfel, T. Neurophotonics 2015, 2, 021008.

(30) Xia, P. Curr. Stem Cell Res. Ther. 2014, 9, 102.

(31) Fernandez-Duenas, V.; Gomez-Soler, M.; Jacobson, K. A.; Kumar, S. T.; Fuxe, K.; Borroto-Escuela, D. O.; Ciruela, F. J. Neurochem. 2012, 123, 373. 


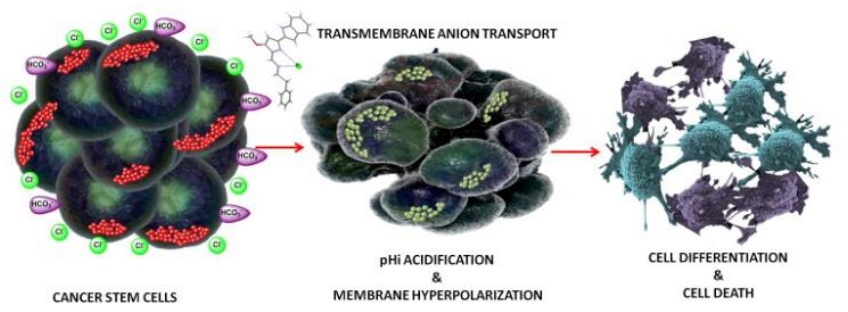

